\title{
A Gastrobronchial Fistula Secondary to Endoscopic Internal Drainage of a Post-Sleeve Gastrectomy Fluid Collection
}

\author{
Paraskevas Gkolfakis, Marc-André Bureau, Marianna Arvanitakis, Jacques Devière, and Daniel Blero \\ Department of Gastroenterology, Hepatopancreatology and Digestive Oncology, Erasme University Hospital, Université Libre de \\ Bruxelles, Brussels, Belgium
}

\begin{abstract}
A 44-year-old woman underwent sleeve gastrectomy, which was complicated by a leak. She was treated with two sessions of endoscopic internal drainage using plastic double-pigtail stents. Her clinical evolution was favorable, but four months after the initial stent placement, she became symptomatic, and a gastrobronchial fistula with the proximal end of the stents invading the diaphragm was diagnosed. She was treated with antibiotics, plastic stents were removed, and a partially covered metallic esophageal stent was placed. Eleven weeks later, the esophageal stent was removed with no evidence of fistula. Inappropriate stent size, position, stenting duration, and persistence of low-grade inflammation could explain the patient's symptoms and provide a mechanism for gradual muscle rupture and fistula formation. Although endoscopic internal drainage is usually safe and effective for the management of post-laparoscopic sleeve gastrectomy leaks, close clinical and radiological follow-up is mandatory. Clin Endosc 2022;55:141-145
\end{abstract}

Key Words: Bariatric endoscopy; Endoscopy complications; Endoscopic internal drainage; Gastrobronchial fistula; Sleeve gastrectomy

\section{INTRODUCTION}

Postoperative leakage is considered to be the most frequent complication after laparoscopic sleeve gastrectomy (LSG), occurring at a rate of $1.9 \%$ to $2.4 \%{ }^{1}$ Leaks are most often the result of proximal staple line disruption and may trigger the formation of intra-abdominal collections.

Leak sealing using a self-expanding metallic stent (SEMS) while simultaneously ensuring adequate percutaneous collection drainage was the first non-surgical therapeutic option proposed for this complication, whereas reintervention was recommended as salvage treatment in non-responding cases. ${ }^{1}$

Received: December 26, 2020 Revised: January 26, 2021

Accepted: February 9, 2021

Correspondence: Paraskevas Gkolfakis

Department of Gastroenterology, Hepatopancreatology and Digestive Oncology, Erasme University Hospital, Université Libre de Bruxelles, Route de Lennik 808, 1070 Brussels, Belgium

Tel: +32-2-555-3712, Fax: +32-2-555-3712, E-mail: pgkolfakis@med.uoa.gr ORCID: https://orcid.org/0000-0002-9677-4013

(c) This is an Open Access article distributed under the terms of the Creative Commons Attribution Non-Commercial License (http://creativecommons.org/ licenses/by-nc/3.0) which permits unrestricted non-commercial use, distribution, and reproduction in any medium, provided the original work is properly cited.
In the last few years, endoscopic internal drainage (EID) of the collection by placing plastic double-pigtail stents (DPS) through the leak site in the gastrointestinal lumen has gained ground. EID is a safe and effective intervention, particularly for early post-bariatric surgery leaks where the collection has not yet been drained percutaneously. ${ }^{2-4}$ However, mild complications (e.g., mucosal lacerations and asymptomatic stent migration) have been reported. ${ }^{3}$ Herein, we describe a case of gastrobronchial fistula (GBF) due to DPS-induced diaphragmatic injury.

\section{CASE REPORT}

A 44-year-old woman underwent LSG for class III obesity (body mass index, $41 \mathrm{~kg} / \mathrm{m}^{2}$ ). On the $3^{\text {rd }}$ postoperative day, she developed abdominal pain associated with fever $\left(38.3^{\circ} \mathrm{C}\right)$ and increased C-reactive protein (CRP) ( $94 \mathrm{mg} / \mathrm{dL})$. A barium swallow study revealed a leak at the level of the gastroesophageal junction, and a computed tomography (CT) scan showed a left subphrenic fluid collection. Antibiotics were administered, and she was transferred to our hospital for further management. At admission, an abdominal drainage tube-placed 
during the operation - was in place, but without communication with the fluid collection. On endoscopy, the leak orifice was identified $1 \mathrm{~cm}$ below the esophagogastric junction at the proximal part of the staple line, and there was no associated stenosis in the upper gastrointestinal lumen. The purulent collection was opacified (Fig. 1A, B) and drained using two $7 \mathrm{Fr}$ $10 \mathrm{~cm}$ DPS (Wilson-Cook Medical Inc., Winston-Salem, NC, USA; Fig. 1C). A nasojejunal feeding tube was left in place for adequate nutrition. Repeat CT scan showed reduction in fluid collection. The patient improved clinically and was discharged one week later.

During the following weeks, she complained of subtle abdominal pain radiating to the left shoulder, even though the inflammatory markers had normalized. On follow-up CT, the collection appeared to have increased in size $(7 \mathrm{~cm})$; thus, we re-evaluated the patient endoscopically to improve EID. Two months after deployment, the initial DPS were removed and three new ones (7 Fr / length 4, 5, and $7 \mathrm{~cm}$ ) were deployed. Contrast injection from the $\sim 5 \mathrm{~mm}$ leak orifice did not reveal a GBF or other complications (Fig. 1D-F).

Unfortunately, two months later, the patient presented with 7 -day onset of nausea and post-prandial productive cough. She was febrile $\left(38^{\circ} \mathrm{C}\right)$ with an increased CRP level $(56 \mathrm{mg} /$ dL). CT showed an increased air-containing fluid collection, exerting a mass effect on the pulmonary parenchyma. Surprisingly, the DPS had migrated and were now invading the diaphragm with their proximal ends located intrathoracically at the level of the pleura (Fig. 2). Esophagogram demonstrated a GBF communicating with the proximal end of the stents. The patient received intravenous antibiotics, and all the stents were retrieved. A $15 \mathrm{~cm}$ partially-covered SEMS (Ultraflex ${ }^{\mathrm{TM}}$; Boston Scientific Corporation, Marlborough, MA, USA) was deployed to cover the leak. A 6 Fr nasocystic catheter was left in the collection for 3 days to facilitate external drainage. Four days later, GBF was still apparent on the esophagogram (Fig. $3 \mathrm{~A})$.

The patient improved progressively during the following weeks, complaining only of intermittent non-productive

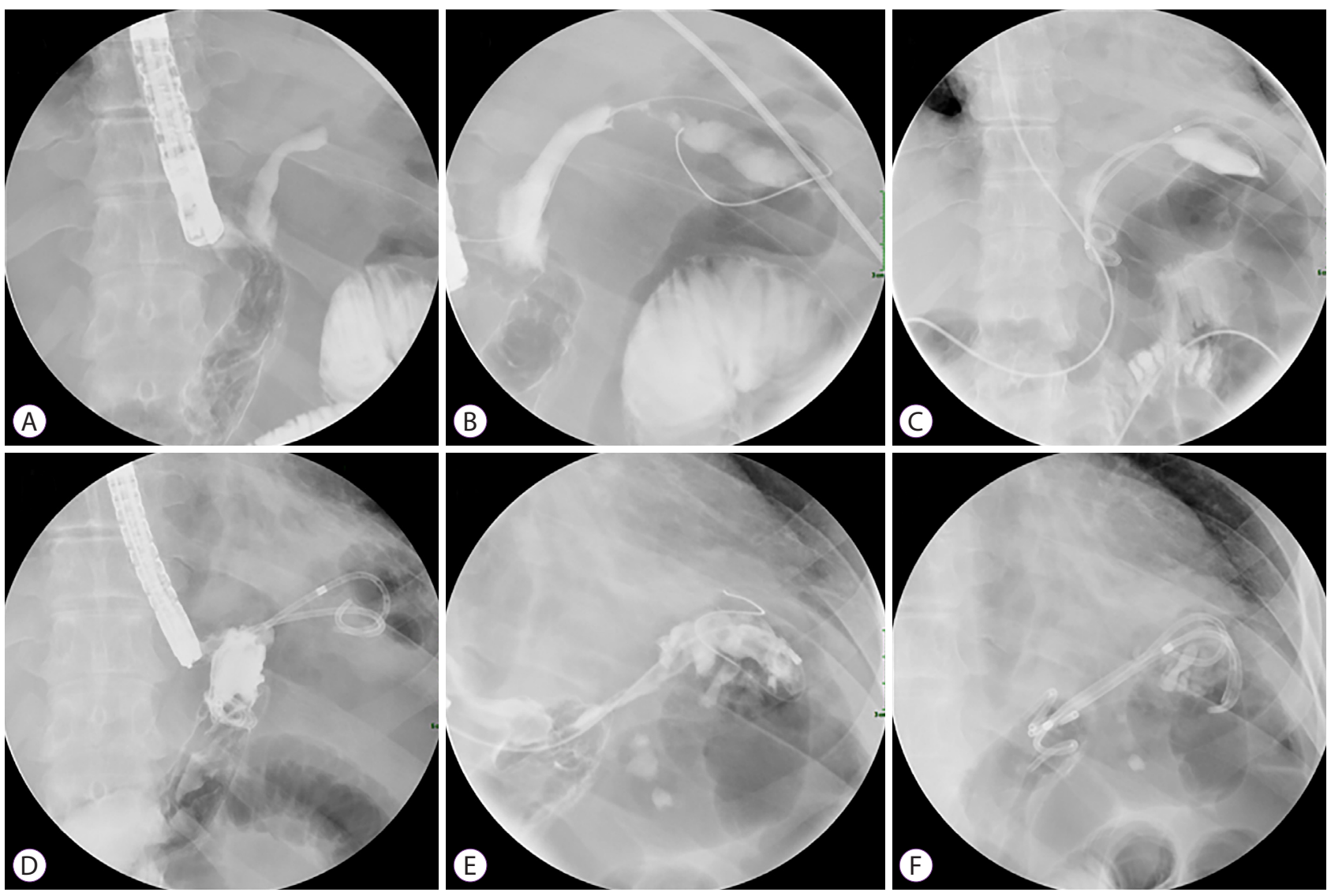

Fig. 1. (A, B) Post-laparoscopic sleeve gastrectomy leak communicating with subphrenic fluid collection appeared opacified during gastroscopy. (C) Endoscopic internal drainage was performed by deployment of two double-pigtail stents with the proximal part in the collection and the distal part in the gastric sleeve. (D) Initial stents were removed endoscopically two months later. $(E)$ Contrast injection showed persistence of collection but no sign of fistula. $(F)$ Deployment of three new stents was done. 

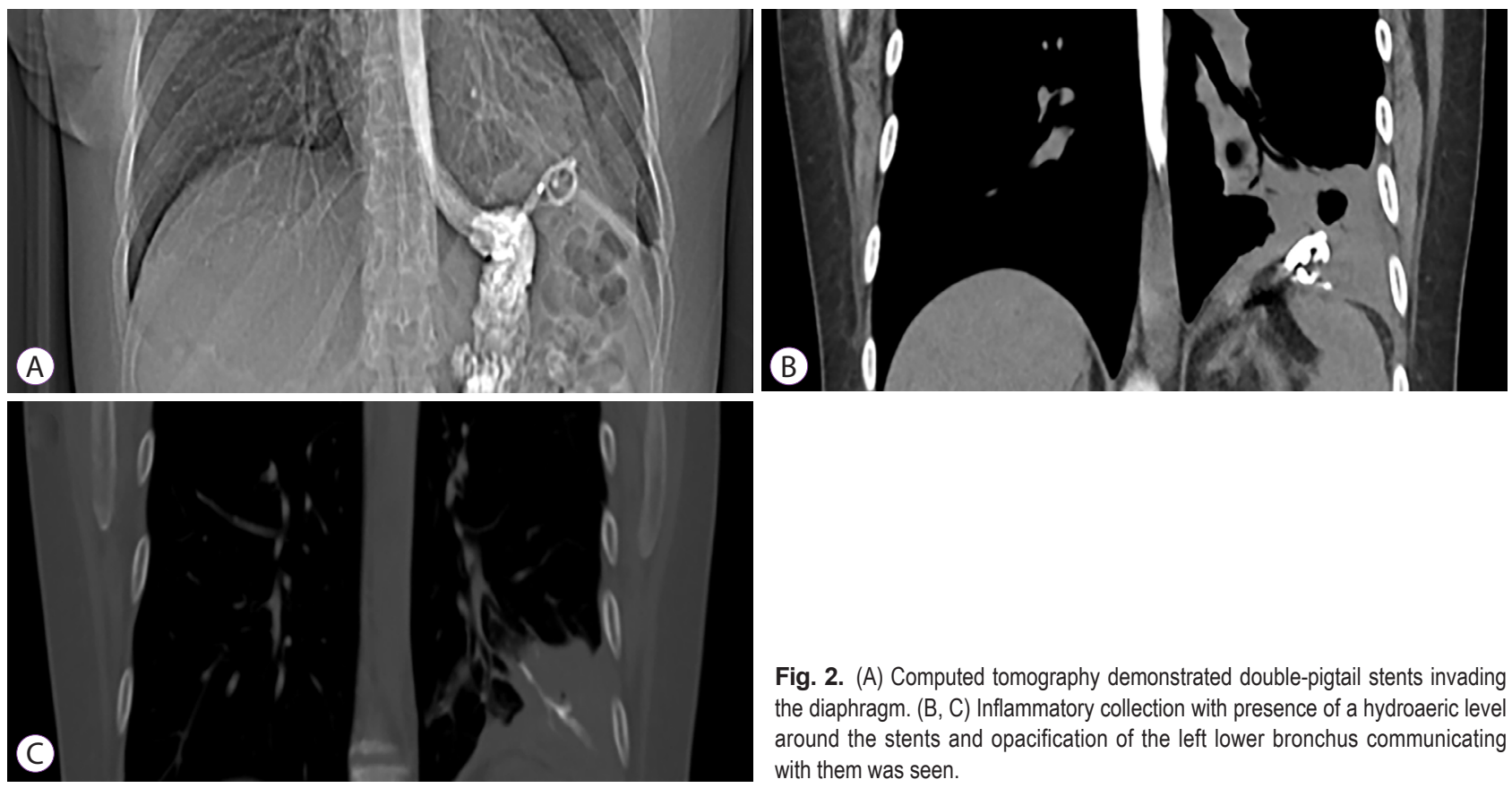

Fig. 2. (A) Computed tomography demonstrated double-pigtail stents invading the diaphragm. (B, C) Inflammatory collection with presence of a hydroaeric level around the stents and opacification of the left lower bronchus communicating with them was seen.
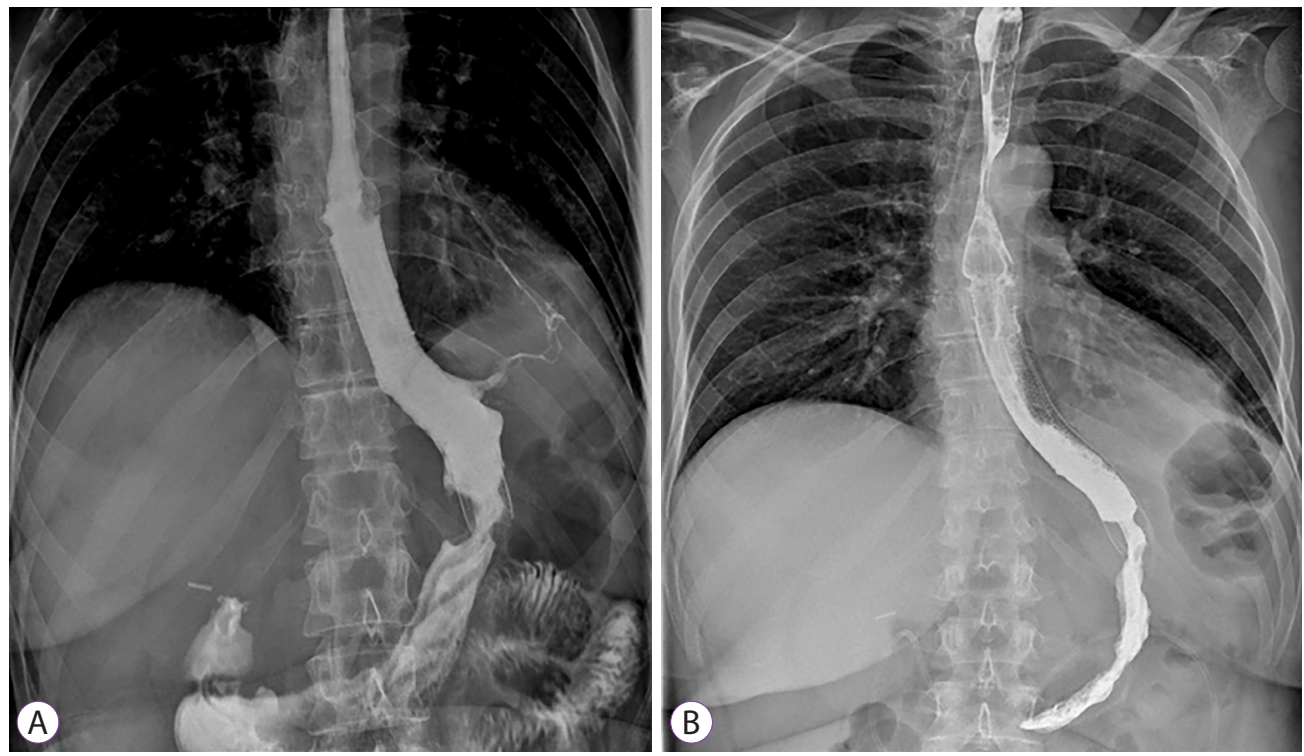

Fig. 3. (A) A gastrobronchial fistula was demonstrated during barium swallow study four days after esophageal stent deployment. (B) Three weeks later, esophagogram showed sealing of the two ends of the esophageal stent with distal and proximal hyperplasia and no sign of fistula persistence was evident.

cough. As expected, tissue overgrowth developed at both ends of the esophageal stent, which permitted sealing of the fistula orifice. There was no sign of a persistent GBF on esophagogram performed 3 weeks after SEMS deployment (Fig. 3B). SEMS was successfully removed using the stent-in-stent technique 11 weeks after deployment (Fig. 4A-C). Contrast injected during this last procedure demonstrated leak closure and the absence of GBF. These findings were confirmed on follow-up esophagogram and CT (Fig. 4D-F). The patient was asymptomatic after the fistula resolution at nine-month follow-up. 

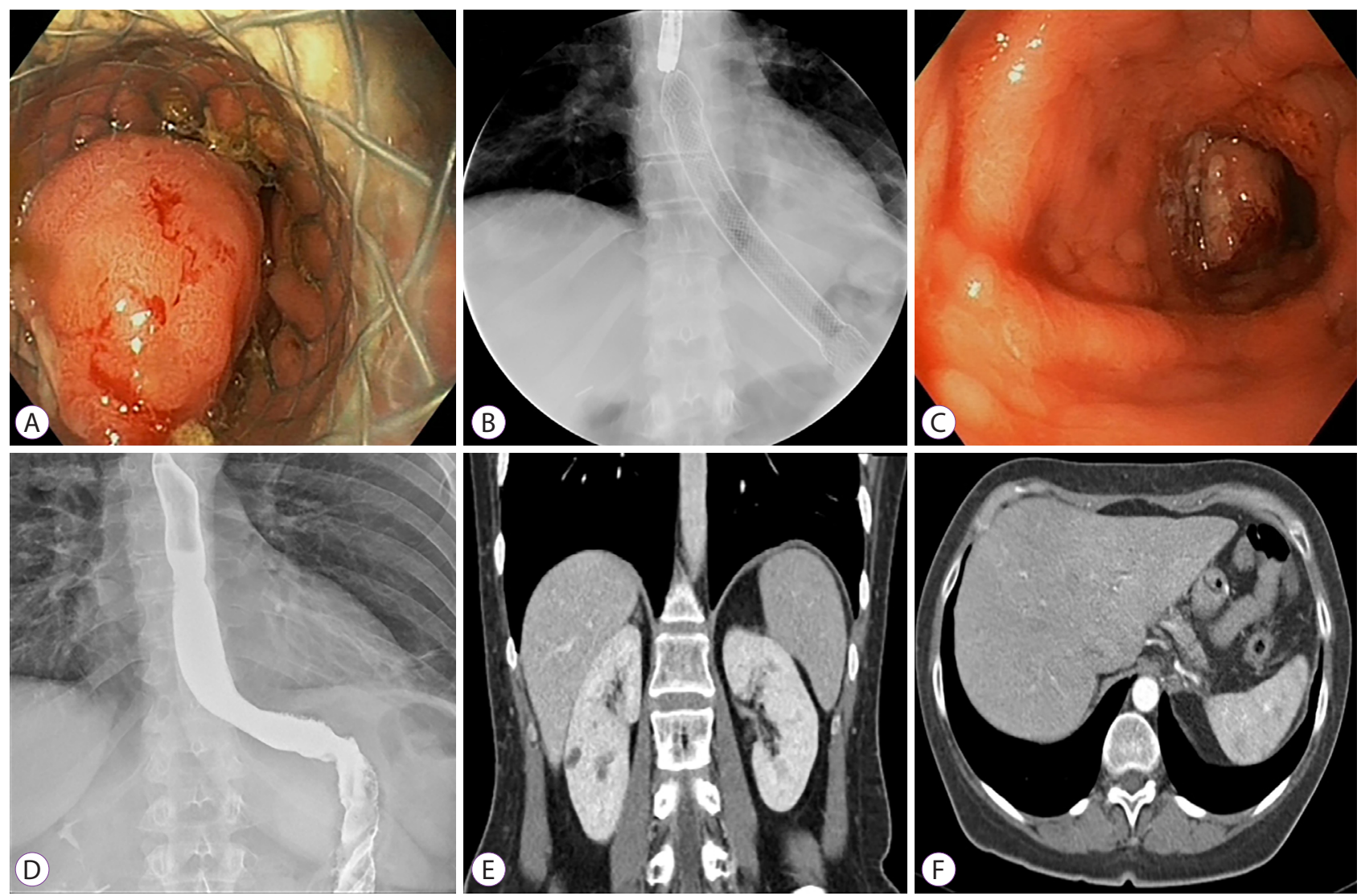

Fig. 4. (A, B, C) A second fully-covered metallic stent was used to remove the initial partially covered esophageal stent (stent-in-stent technique). (D, E, F) Follow-up esophagogram and computed tomography showed no evidence of residual fistula.

\section{DISCUSSION}

GBF is a rare but severe complication of LSG leak. ${ }^{5}$ It is usually the result of a chronic subphrenic collection leading to pulmonary abscess and fistula formation. It should be suspected in every patient who has undergone LSG and presents with respiratory symptoms, including productive cough and thoracic pain. Cross-sectional imaging is used as the first diagnostic modality to identify any associated inflammatory collection and, when combined with swallowing of oral contrast, it may delineate the fistula tract. Unfortunately, GBF is associated with severe lung infections and significant morbidity. Various endoscopic treatment modalities have been proposed, including deployment of esophageal stents, injection of fibrin glue, and balloon dilation or stricturotomy for treating associated stenosis. However, an important number of cases will eventually necessitate an advanced surgical approach, including thoracotomy and partial or total gastrectomy. In a recent review, 36 cases of post-bariatric (24 post-LSG) GBF were identified. ${ }^{4}$ Multiple endoscopic treatments were employed for 20 patients, leading to GBF resolution in 18 of them, while a definite surgical approach was chosen for 17 patients. Among them, an aggressive surgical treatment, thoracotomy, rib resection, and diaphragm resection, was applied in 14 patients and this was associated with more complications compared to the endoscopic treatment. ${ }^{4}$

Besides medical treatment, EID, esophageal stenting, and other endoscopic treatments have been used to treat postLSG leaks. ${ }^{1}$ EID allows intraluminal drainage of the collection and DPS not only partially seals the orifice, thus, preventing food particle migration, but also acts as a foreign body inducing granulation tissue formation and fistula reepithelization. ${ }^{6}$ EID's place in the leak management algorithm remains unclear. Some authors have proposed EID in both drained and non-drained collections regardless of the size of the orifice, ${ }^{3,7}$ whereas others recommend its use only in non-drained collections. ${ }^{1,8}$ EID has mainly been used for acute/early leaks, and its clinical success rate ranges from $78 \%$ to $84 \% .{ }^{2,3,8,9}$ 
Both mild, such as esophageal ulcerations, dysphagia, and bleeding, and severe complications like spleen invasion ${ }^{10}$ and perforation, occur in 5\% of the EID-treated patients. Most patients are treated conservatively with stent removal without affecting the treatment outcome. ${ }^{3}$ However, these complications justify careful follow-up, especially in patients complaining of residual pain with the stent in place, as in our case. Our patient complained of left shoulder pain two months prior to developing a productive cough. New onset of pain, which is typical for diaphragmatic injury, should always lead to a review of treatment adequacy.

In our case, we identified some stent and disease-related factors that could have contributed to the GBF formation. The initial DPS length $(10 \mathrm{~cm})$ was chosen to permit adequate drainage of the subphrenic parasplenic collection, which may have been too long, causing continuous friction between the proximal end and the diaphragm. Moreover, tissues surrounding the collection (including the diaphragm crus) are also more fragile and prone to trauma due to persistent inflammation.

In conclusion, this case highlights the need for close clinical follow-up, the importance of tailoring treatment to clinical presentation, and the ability to change strategy in case of complications. It also illustrates that even complex GBF can be treated, if a multidisciplinary approach is taken, following more conservative approaches such as endoscopy and medical treatment.

Conflicts of Interest

The authors have no potential conflicts of interest.

Funding

None.

\section{Acknowledgments}

We would like to acknowledge the contribution of a medical writer, Sandy Field, $\mathrm{PhD}$, for English language editing and formatting of this manuscript.
Author Contributions

Conceptualization: Daniel Blero, Paraskevas Gkolfakis

Data curation: PG, Marc-André Bureau

Formal analysis: PG, MAB

Writing-review\&editing: PG, MAB, Marianna Arvanitakis, Jacques Devière, DB

\section{ORCID}

Paraskevas Gkolfakis

Marc-André Bureau

Marianna Arvanitakis

Jacques Devière

Daniel Blero https://orcid.org/0000-0002-9677-4013 https://orcid.org/0000-0001-6978-258X https://orcid.org/0000-0001-7112-4383 https://orcid.org/0000-0003-1889-1924 https://orcid.org/0000-0003-1173-8724

\section{REFERENCES}

1. Eisendrath P, Deviere J. Major complications of bariatric surgery: endoscopy as first-line treatment. Nat Rev Gastroenterol Hepatol 2015;12:701710 .

2. Donatelli G, Dumont JL, Cereatti F, et al. Endoscopic internal drainage as first-line treatment for fistula following gastrointestinal surgery: a case series. Endosc Int Open 2016;4:E647-E651.

3. Gonzalez JM, Lorenzo D, Guilbaud T, Bege T, Barthet M. Internal endoscopic drainage as first line or second line treatment in case of postsleeve gastrectomy fistulas. Endosc Int Open 2018;6:E745-E750.

4. Silva LB, Moon RC, Teixeira AF, et al. Gastrobronchial fistula in sleeve gastrectomy and roux-en-y gastric bypass--a systematic review. Obes Surg 2015;25:1959-1965.

5. Siddique I, Alazmi W, Al-Sabah S. Endoscopic internal drainage by double pigtail stents in the management of laparoscopic sleeve gastrectomy leaks. Surg Obes Relat Dis 2020;16:831-838.

6. Donatelli G, Ferretti S, Vergeau BM, et al. Endoscopic internal drainage with enteral nutrition (EDEN) for treatment of leaks following sleeve gastrectomy. Obes Surg 2014;24:1400-1407.

7. Donatelli G, Catheline JM, Dumont JL, et al. Outcome of leaks after sleeve gastrectomy based on a new algorithm addressing leak size and gastric stenosis. Obes Surg 2015;25:1258-1260.

8. Bouchard S, Eisendrath P, Toussaint E, et al. Trans-fistulary endoscopic drainage for post-bariatric abdominal collections communicating with the upper gastrointestinal tract. Endoscopy 2016;48:809-816.

9. Lorenzo D, Guilbaud T, Gonzalez JM, et al. Endoscopic treatment of fistulas after sleeve gastrectomy: a comparison of internal drainage versus closure. Gastrointest Endosc 2018;87:429-437.

10. Donatelli G, Airinei G, Poupardin E, et al. Double-pigtail stent migration invading the spleen: rare potentially fatal complication of endoscopic internal drainage for sleeve gastrectomy leak. Endoscopy 2016;48(Suppl 1 UCTN): E74-E75. 